\section{Invasive thymoma with pure red cell aplasia and amegakaryocytic thrombocytopenia}

\author{
Takuya Onuki, ${ }^{1}$ Yusuke Kiyoki, ${ }^{2}$ \\ Sho Ueda, ${ }^{1}$ Masatoshi Yamaoka, ${ }^{1}$ \\ Seiich Shimizu, ${ }^{2}$ Masaharu Inagaki ${ }^{1}$ \\ 1Department of General Thoracic Surgery, \\ and ${ }^{2}$ Department of Hematology, \\ Tsuchiura Kyodo General Hospital, \\ Ibaraki, Japan
}

\section{Abstract}

We here describe a case involving a 67-yearold female patient who was referred to our hospital due to severe anemia (hemoglobin, 5.0 $\mathrm{g} / \mathrm{dL}$ ), thrombocytopenia (platelet count, $0.6 \times 10^{4} / \mu \mathrm{L}$ ), and a mediastinal shadow with calcification noted on X-ray. On admission, an anterior mediastinal tumor was detected, and bone marrow biopsy revealed few megakaryocytes and severely reduced numbers of erythroid cells. The diagnosis was thymoma with pure red cell aplasia (PRCA) and acquired amegakaryocytic thrombocytopenia (AAMT). On Day 8 of admission, the patient received immunosuppressive therapy together with cyclosporine for the 2 severe hematologic diseases, which were stabilized within 2 months. Subsequently, total thymectomy was performed. The diagnosis of the tumor invading the left lung was invasive thymoma, MasaokaKoga stage III. The histological diagnosis was World Health Organization type AB. Thymoma accompanied with PRCA and AAMT is very rare, and, based on our case, immunotherapeutic therapy for the hematologic disorders should precede surgical intervention.

\section{Introduction}

We here present a rare case of thymoma accompanied by concomitant pure red cell aplasia (PRCA) and acquired amegakaryocytic thrombocytopenia (AAMT). In this case, the hematologic disorders could be controlled with immunosuppressive therapy followed by total thymectomy.

\section{Case Report}

A 67-year-old, non-smoking woman, with no remarkable disease history, visited her local doctor complaining of general malaise and severe edema of the bilateral lower extremities for 3 days. There, she received blood count and chest X-ray examinations. These examinations revealed severe anemia, thrombocytopenia, and a mediastinal shadow with calcification. She did not present bleeding tendency. Consequently, she was referred to the Department of Hematology at our hospital. On the day of admission (Day 1), the complete blood count (CBC) results were as follows: hemoglobin $(\mathrm{Hb}), 5.0 \mathrm{~g} / \mathrm{dL}$; red blood cell count, $129 \times 10^{4} / \mu \mathrm{L}$; hematocrit, $15.3 \%$; mean corpuscular volume, $118.0 \mathrm{fL}$; reticulocytes, $1.3 \%$; white blood cell count, $4860 / \mathrm{mm}^{3}$ with 46.0\% neutrophils; and platelet count (PIt), $0.6 \times 10^{4} / \mu \mathrm{L}$. The blood biochemical results were as follows: lactate dehydrogenase, 290 IU/L; ferritin, $196 \mathrm{ng} / \mathrm{mL}$; haptoglobin, 117 $\mathrm{mg} / \mathrm{dL}$; vitamin $\mathrm{B}_{12}, 676 \mathrm{pg} / \mathrm{mL}$; and folate, 20.1 $\mathrm{ng} / \mathrm{mL}$. The direct Coombs test yielded a weak positive. The patient received urgent transfusion of red cell concentrate and platelet concentrate. The mediastinal shadow was examined by chest computed tomography on Day 2, which revealed a tumor, $39 \times 17 \times 60 \mathrm{~mm}$ in size, with central calcification (Figure 1A). The tumor was distant from superior vena cava and inferior vena cava, the cause of her edema was suspected as severe anemia. This tumor was strongly suspected as thymoma. The serum anti-acetylcholine receptor antibody and immunoglobulin levels were examined to exclude thymoma-related autoimmune diseases such as myasthenia gravis and hypogammaglobulinemia. The anti-acetylcholine receptor antibody and the immunoglobulin levels were within the normal ranges.

Subsequently, the patient was referred to the Department of General Thoracic Surgery. Bone marrow biopsy was performed on Day 3. Microscopic examination of the bone marrow samples showed that the bone marrow was hypoplastic, and megakaryocytes were scarce (Figure 2A). Glycophorin A staining revealed decreased erythroid cell numbers (Figure 2B), while myeloperoxidase staining revealed adequate numbers of myeloid cells (Figure 2C). The ratio of myeloid cells to erythroblast cells in the bone marrow aspirate was 51. After excluding common causes of anemia, and despite the reticulocyte count seeming higher than that normally observed in PRCA, the existence of thymoma and the findings of the bone marrow specimen led to a diagnosis of thymoma with PRCA. The patient's thrombocytopenia was diagnosed as AAMT on the basis of the scarcity of megakaryocytes in the bone marrow, which excluded common diseases presenting with thrombocytopenia. Because the patient had a normal white blood cell count and myeloid cell population, aplastic anemia was tentatively ruled out. Treatment for PRCA
Correspondence: Takuya Onuki, Department of General Thoracic Surgery, Tsuchiura Kyodo General Hospital, 4-1 Ohtsuno, Tsuchiura City, Ibaraki 300-0028, Japan.

Tel.: +81.29.830.3711 - Fax: +81.29.846.3721.

E-mail: onukitakuya@hotmail.com

Key words: Amegakaryocytic thrombocytopenia, Cyclosporine, Pure red cell aplasia, Thymoma.

Contributions: TO, SU, MY, and MI contributed to the surgical treatment of the thymoma; YK, SS contributed to the treatment of the hematologic disorders.

Conflict of interest: the authors declare no conflict of interest.

Received for publication: 30 July 2016

Revision received: 13 October 2016.

Accepted for publication: 10 November 2016.

This work is licensed under a Creative Commons Attribution-NonCommercial 4.0 International License (CC BY-NC 4.0).

(C) Copyright T. Onuki et al., 2016

Licensee PAGEPress, Italy

Hematology Reports 2016; 8:6680

doi:10.4081/hr.2016.6680

and AAMT with immunosuppressive therapy comprising cyclosporine (CYA) was started on Day 8. At this time, the patient's weight was 45 $\mathrm{kg}$ and her renal function was normal. Thus, CYA was given at a dose of $300 \mathrm{mg} /$ day, with the appropriate serum concentration of CYA set as $200 \mathrm{ng} / \mathrm{mL}$. Final blood transfusions of red cell concentrate and platelet concentrate were performed on Days 11 and 23, respectively. The CBC on Day 52 showed $\mathrm{Hb}$ and Plt levels of $9.3 \mathrm{~g} / \mathrm{dL}$ and $17.6 \times 10^{4} / \mu \mathrm{L}$, respectively, which reflected appropriate stabilization (Figure 3). Total thymectomy via median sternotomy was performed on Day 71. The tumor showed direct invasion of the left lung in the left thoracic cavity (Figure 1B), and the invaded lung tissue was thus also resected. The pathological diagnosis of the tumor was invasive thymoma; the histological subtype was World Health Organization type AB (Figure 1C and 1D), and it was categorized as MasaokaKoga stage III. Postoperative radiotherapy $(50.0 \mathrm{~Gy})$ of the tumor bed was performed following the surgical intervention. A bone marrow biopsy was re-performed on Day 226; evaluation revealed that the hypoplasia had resolved completely, and adequate megakaryocytes were observed (Figure 2D). At this time, the $\mathrm{CBC}$ results were as follows: $\mathrm{Hb}, 9.8 \mathrm{~g} / \mathrm{dL}$; red blood cell count, $323 \times 10^{4} / \mu \mathrm{L}$; hematocrit, $30.0 \%$; mean corpuscular volume, $92.9 \mathrm{fL}$; reticulocytes, 0.7\%; white blood cell count, $2560 / \mathrm{mm}^{3}$ with $74.6 \%$ neutrophils; and Plt, 
$2.04 \times 10^{4} / \mu \mathrm{L}$. At the latest follow-up, one year after CYA was started, the patient's hematological disorders and thymoma have not recurred.

\section{Discussion}

The most common cause of thymoma-related cytopenia is PRCA; approximately $2 \%$ of thymoma patients present with PRCA, and $20 \%$ of PRCA patients reportedly have a concomitant thymoma. In these cases, PRCA is thought to result from T-cell mediated damage of erythroid progenitor or precursor cells. ${ }^{1-3}$ Immunosuppressive therapy is the most effective treatment for PRCA, while total thymectomy has been reported to be less effective. ${ }^{2}$

Our case of thymoma and PRCA was further complicated by AAMT. AAMT is a rare hematologic and immune-mediated disorder. It has been reported that certain disorders involving the immune system, such as thymomas or large granular lymphocytic leukemia, can occur in combination with PRCA or AAMT. ${ }^{4}$ However, the autoimmune mechanism of thymoma-related AAMT in relation to PRCA remains unclear. In addition, cases of thymoma and idiopathic thrombocytopenic purpura have also been published. ${ }^{5}$ of note, in these cases, premature platelets were destroyed by the reticuloendothelial system as a result of the idiopathic thrombocytopenic purpura, resulting in peripheral blood thrombocytopenia, which is critically different from AAMT. Limited case reports on the coexistence of thymoma, PRCA, and AAMT, a seen in our case, have been published..$^{3,6-8}$ These cases are summarized in Table 1. Unlike in our case, however, in which all conditions occurred simultaneously, in each of these previous cases, the diseases occurred separately, indicating that thymoma-related hematologic disorders can change over time. Moreover, some of these cases further co-existed with other autoimmune diseases, such as myasthenia gravis.
Some investigators have recommended treating with CYA for PRCA and AAMT, ${ }^{9}$ but few reports have discuss the appropriate treatment strategy for thymoma complicated by these two hematologic disorders. Our treatment strategy for this patient was as follows: although total thymectomy for the mediastinal tumor suspected to be a thymoma was desirable, surgical intervention in the presence of severe anemia and thrombocytopenia was contraindicated. In addition, postponing surgical intervention was not considered a critical issue, because thymomas are characterized by lower malignancy and more indolent growth than thymic carcinomas. Therefore, we first addressed the most
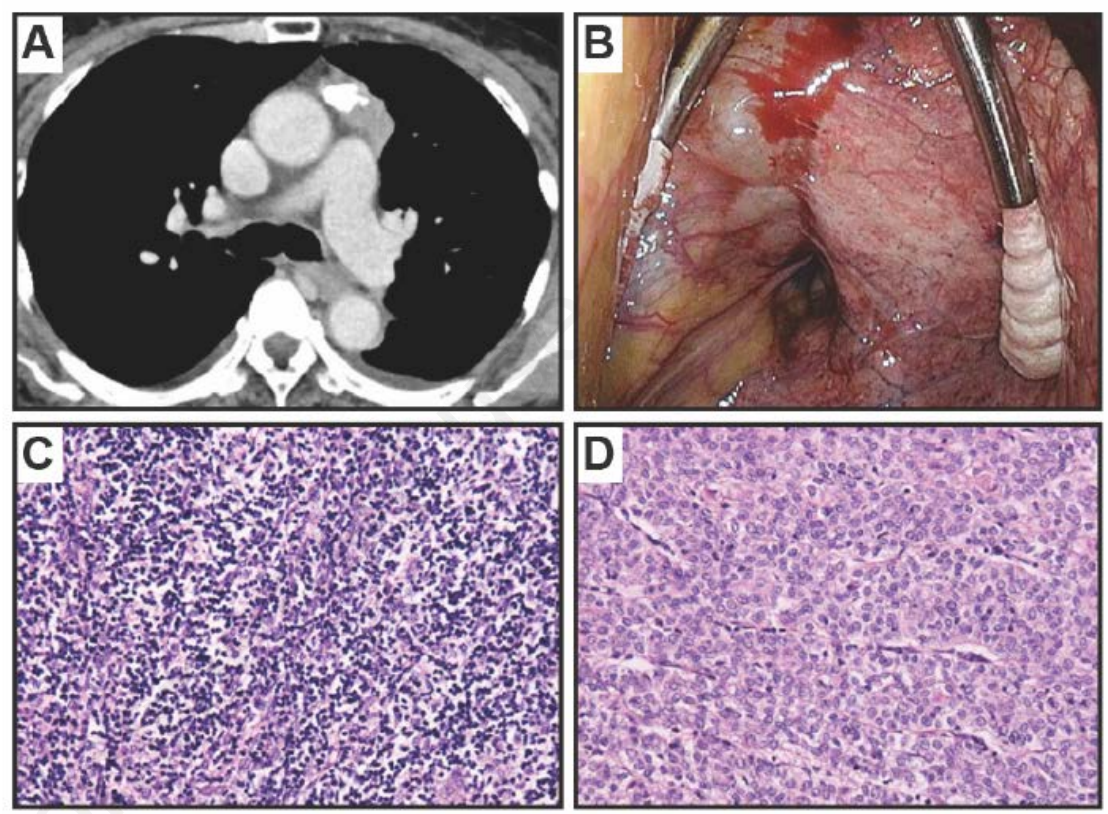

Figure 1. A) Chest computed tomography showing an anterior mediastinal tumor with calcification. The size of the tumor was $39 \times 17 \times 60 \mathrm{~mm}$. B) Surgical view of the anterior mediastinum in the left cavity. There is direct invasion of the left lung by the tumor. C) and D) Microscopic images of the tumor (hematoxylin and eosin stain, high-power field). The final diagnosis was invasive thymoma, with a histological subtype of World Health Organization type AB. The type $A$ area is shown in (C) and the type $B$ area in (D).

Table 1. Published cases of combined thymoma, pure red cell aplasia, and acquired amegakaryocytic thrombocytopenia.

\begin{tabular}{|c|c|c|c|c|}
\hline Author (year) & $\begin{array}{l}\text { Disease progression } \\
\text { (past > recent) }\end{array}$ & $\begin{array}{l}\text { Therapy for } \\
\text { thymoma }\end{array}$ & $\begin{array}{l}\text { Immunosuppressive } \\
\text { therapy for PRCA and AAMT }\end{array}$ & $\begin{array}{l}\text { Other } \\
\text { autoimmune }\end{array}$ \\
\hline Maslovsky (2005) & $\begin{array}{l}\text { MG > Thymoma and PRCA > } \\
\text { AAMT > Aplastic anemia }\end{array}$ & $\begin{array}{l}\text { Partial tumor resection } \\
\text { and chemotherapy }\end{array}$ & $\begin{array}{l}\text { Steroid before therapy and } \\
\text { chemotherapy (details unknown) }\end{array}$ & $\begin{array}{l}\text { MG (10 years before } \\
\text { PRCA); Aplastic anemia } \\
\text { (one year after PRCA) }\end{array}$ \\
\hline Cho (2010) & Thymoma > PRCA and AAMT & Thymectomy & Steroid before thymectomy & None \\
\hline Gay (2014) & $\begin{array}{l}\text { Thymoma > Thymoma } \\
\text { recurrence > PRCA and AAMT }\end{array}$ & $\begin{array}{l}\text { Thymectomy for the primary tumor, } \\
\text { chemotherapy for recurrence }\end{array}$ & $\begin{array}{l}\text { CYA, corticosteroid, and } \\
\text { antithymocyte globulin }\end{array}$ & None \\
\hline Fujiwara (2015) & $\begin{array}{l}\text { Thymoma and PRCA }> \\
\text { MG > AAMT }\end{array}$ & $\begin{array}{l}\text { Chemotherapy followed by } \\
\text { radical resection }\end{array}$ & $\begin{array}{l}\text { CYA after the onset of AAMT } \\
\text { (before surgery) }\end{array}$ & MG (during chemotherapy) \\
\hline Our case & $\begin{array}{l}\text { Thymoma, PRCA, and AAMT } \\
\text { (simultaneous occurrence) }\end{array}$ & Thymectomy & CYA before thymectomy & None \\
\hline
\end{tabular}

PRCA: pure red cell aplasia, AAMT: acquired amegakaryocytic thrombocytopenia, MG: myasthenia gravis, CYA: cyclosporine. 

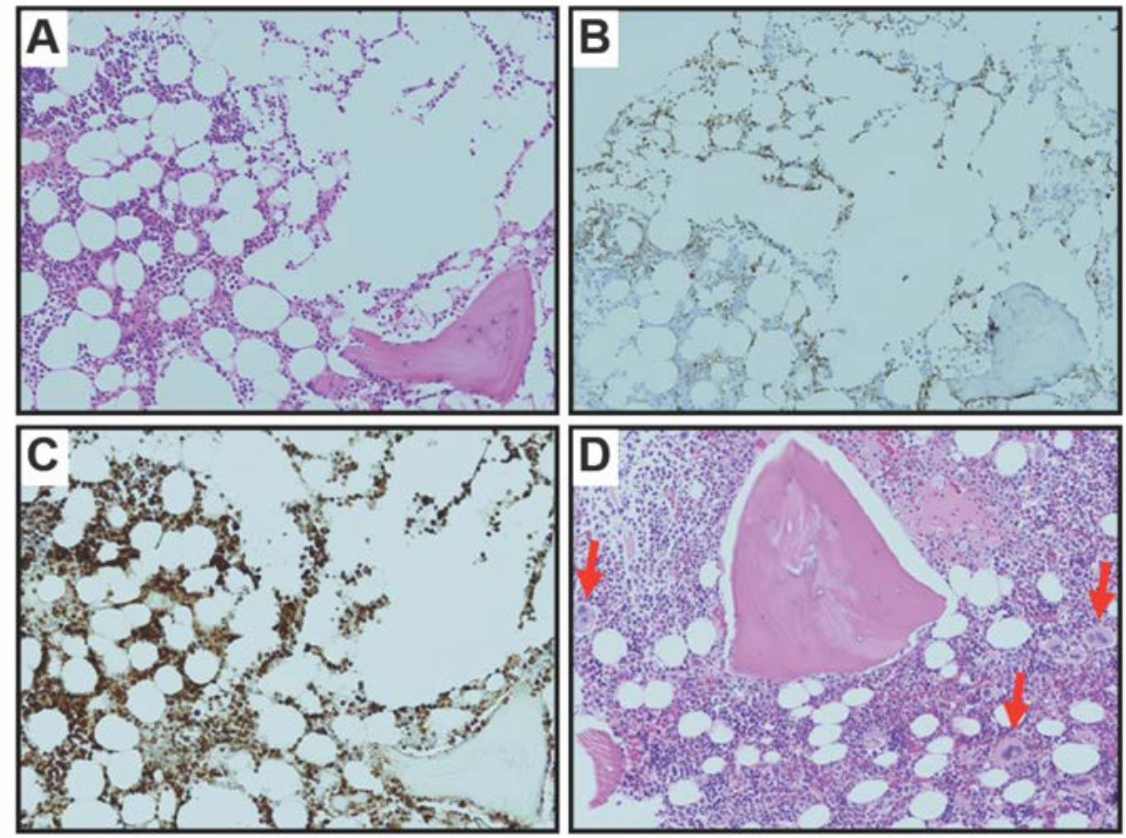

Figure 2. Histopathological images of the bone marrow. A) Bone marrow biopsy section, obtained on Day 3 after hospital admission, showing hypoplasia and scant megakaryocytes (hematoxylin and eosin stain). B) Glycophorin A staining revealed decreased erythroid numbers. C) Myeloperoxidase staining revealed adequate numbers of myeloid cells. D) Repeat bone marrow biopsy section obtained on Day 226 revealed that the hypoplasia had resolved, and many megakaryocytes can be seen (arrow) (hematoxylin and eosin stain).

present case, we conclude that, for successful treatment, the hematologic disorders have to be controlled before surgery for the thymoma.

\section{References}

1. Kondo K, Monden Y. Thymoma and myasthenia gravis: a clinical study of 1,089 patients from Japan. Ann Thorac Surg 2005;79:219-24.

2. Hirokawa M, Sawada K, Fujishima N, et al. PRCA Collaborative Study Group. Long- term outcome of patients with acquired chronic pure red cell aplasia (PRCA) following immunosuppressive therapy: a final report of the nationwide cohort study in 2004/2006 by the Japan PRCA collaborative study group. Br J Haematol 2015;169: 879-86.

3. Gay CM, William WN Jr, Wang SA, et al. Thymoma complicated by acquired amegakaryocytic thrombocytopenia and pure red cell aplasia. J Natl Compr Canc Netw 2014;12:1505-9.

4. Agarwal N, Spahr JE, Werner TL, et al. Acquired amegakaryocytic thrombocytopenic purpura. Am J Hematol 2006;81: 132-5.

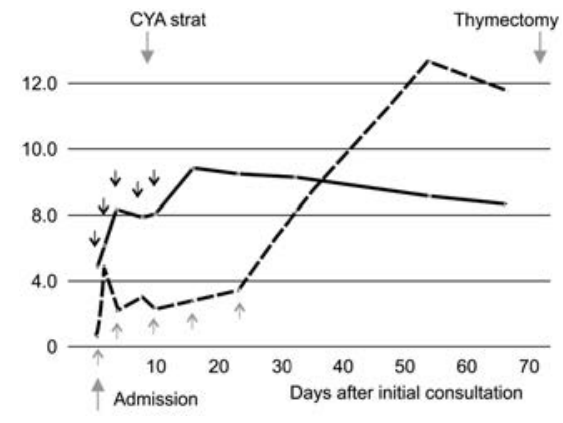

Figure 3. Behaviors of hemoglobin and platelets from the time of admission to thymectomy. The black and broken lines indicate hemoglobin $(\mathrm{g} / \mathrm{dL})$ and platelets $\left(\times 10^{4} / \mu \mathrm{L}\right)$, respectively. The arrows indicate the blood transfusion of red cell concentrate and platelet concentrate. CYA: cyclosporine.

5. Qin J, Liu L. Thymoma with idiopathic thrombocytopenic purpura: report of a case. J Thorac Cardiovasc Surg 2005;129:453.

6. Maslovsky I, Gefel D, Uriev L, et al. Malignant thymoma complicated by amegakaryocytic thrombocytopenic purpura. Eur J Intern Med 2005;16:523-4.

7. Cho AR, Cha YJ, Kim HR, et al. Acquired amegakaryocytic thrombocytopenia after thymectomy in a case of pure red cell aplasia associated with thymoma. Korean $\mathrm{J}$ Lab Med 2010;30:244-8 [Article in Korean].

8. Fujiwara $\mathrm{A}$, Inoue $\mathrm{M}$, Kusumoto $\mathrm{H}$, et al. Myasthenic crisis caused by preoperative chemotherapy with steroid for advanced thymoma. Ann Thorac Surg 2015;99:e11-3.

9. Lai DW, Loughran TP Jr, Maciejewski JP, et al. Acquired amegakaryocytic thrombocytopenia and pure red cell aplasia associated with an occult large granular lymphocyte leukemia. Leuk Res 2008;32:823-7. 